\title{
A AGROINDÚSTRIA FAMILIAR E AS REGULAMENTAÇÕES SANITÁRIAS: ANÁLISE DA APLICABILIDADADE DA RESOLU̧ÇÃO 49/2013 EM UM MUNICÍPIO DO SUDOESTE DO PARANÁ
}

\author{
Aline Luiza Führ ${ }^{1}$ \\ Neiva Aparecida Ancini² \\ Rozane Márcia Triches ${ }^{3}$
}

\begin{abstract}
RESUMO
O objetivo deste trabalho foi analisar as condições de agricultores familiares e microempreendedores e a competência do órgão de Vigilância Sanitária em relação às considerações trazidas pela Resolução da Diretoria Colegiada (RDC) no-49/2013. Trata-se de um estudo de caso quantitativo e qualitativo, realizado em um município do sudoeste do Paraná. Foram realizadas entrevistas semiestruturadas diferenciadas de acordo com o grupo de indivíduos e analisadas com a técnica de análise de conteúdo e aplicado o checklist/RDC n275/2002 nos estabelecimentos. Três de quatro estabelecimentos foram classificados no grupo 3 - com apenas 0 $50 \%$ dos itens atendidos, constatando-se que esta RDC não é aplicável à realidade de pequenas agroindústrias familiares. O profissional da Vigilância Sanitária, mesmo sem conhecer a RDC $\mathrm{n} \div 49$, seguia algumas diretrizes, principalmente a da razoabilidade. Considerando-se os aspectos retratados pela Resolução, bem como, os impasses diagnosticados, verificou-se pouco conhecimento, aderência, praticabilidade e, portanto, efetividade desta política no caso estudado e a necessidade de esclarecer mais os atores envolvidos para que a mesma atinja seus objetivos.
\end{abstract}

Palavras-chave: Vigilância Sanitária, agricultura familiar, políticas públicas, agroindústria, segurança alimentar e nutricional.

\section{FAMILY AGROINDUSTRY AND HEALTH REGULATIONS: ANALYSIS OF THEAPPLICABILITY OF RESOLUTION 49/2013 IN A SOUTHEAST PARANÁMUNICIPALITY}

\footnotetext{
ABSTRACT

The aim this studywas to analyze the conditions of family farmers and microentrepreneurs and the competence of the Health Surveillance agencyregarding the considerations brought by Resolution of the Collegiate Board (RDC) no49 / 2013. This is a quantitative and qualitative case study, conducted in a municipality in southwestern Paraná. Semi-structured interviews were conducted according to the

${ }^{1}$ Graduada em Nutrição (UFFS). Especialista em Saúde da Família (UNILA). Mestranda em Ciência de Alimentos (UEM). E-mail: alineluizafuhr@gmail.com

${ }^{2}$ Graduada em Nutrição (UFFS). E-mail: neivaeguilherme@gmail.com

${ }^{3}$ Graduada em Nutrição (UNIJUÍ). Mestrado em Epidemiologia (UFRGS). Doutorado em Desenvolvimento Rural (UFRGS). Docente do Curso de Nutrição e do Programa de Pós-Graduação em Agroecologia e Desenvolvimento Rural Sustentável (UFFS).E-mail: rozane.triches@uffs.edu.br
} 
group of individuals and analyzed using the content analysis technique and applied checklist/RDC No. $2775 / 2002$ in the places. Three out of four markets were classified in group 3 - with only $0-50 \%$ of the items served, noting that this DRC is not applicable to the reality of small family agribusiness. The Health Surveillance professional, even without knowing RDC No. 49, followed some guidelines, especially reasonableness. Considering the aspects portrayed by the Resolution, as well as the impasses diagnosed, there was little knowledge, adherence, practicability and, therefore, the effectiveness of this policy in the case studied and the need to further clarify the actors involved in order for it to reach its goals.

Keywords: Health Surveillance, family farming, public policy, agroindustry, nutritional and food security.

\section{INTRODUÇÃO}

A Segurança Alimentar e Nutricional (SAN), ao longo das duas últimas décadas, vem ganhando progressiva relevância na agenda pública ao incorporar os princípios do direito humano à alimentação adequada (DHAA) e da soberania alimentar. Neste âmbito, um dos avanços trazidos pela Política Nacional de Segurança Alimentar e Nutricional (PNSAN) refere-se ao fortalecimento da agricultura familiar e a reconexão entre a produção e consumo (SCHOTTZ; CINTRÃO; SANTOS, 2015).

A valorização para continuidade da produção de base familiar desponta como uma forma de manutenção da cultura, costumes, hábitos e conhecimentos tradicionais. Nesse sentido, Programas como o Programa de Aquisição de Alimentos (PAA) e Programa Nacional de Alimentação Escolar (PNAE) têm sido estratégicos para o incentivo à agricultura familiar, tendo em vista que oferecem vantagens como a garantia da compra dos gêneros produzidos e incremento à renda destes agricultores (SILVA e FERREIRA, 2016; BEVILAQUA e TRICHES, 2014).

Todavia, este segmento de produção de alimentos, que possui destacável importância econômica e social para a SAN, convive com bloqueios no acesso aos mercados formal e institucional (especialmente PAA e PNAE), devido à dificuldade de adequação às normas sanitárias vigentes, não compatíveis com a realidade vivenciada (SCHOTTZ; CINTRÃO; SANTOS, 2014; TRICHES, SCHNEIDER, 2010a).

De acordo com Cruz e Schneider (2010) as exigências, em termos de escala e infraestrutura para a legalização desses produtos nos moldes convencionais, tornam inacessível a inserção da grande maioria dos agricultores familiares no sistema produtivo formal, o que faz com que se restrinjam aos mercados informais. Os autores ressaltam que, enquanto as mesmas normas, critérios e parâmetros, em termos de estrutura física e exigências legais (sanitárias, fiscais) forem aplicadas às escalas de produção díspares (impérios ou corporações alimentares e produtos tradicionais artesanais característicos de cada região) a tendência será atrelar a qualidade às grandes corporações, enquanto caberá à produção em pequena escala, o título de informal.

Para Medeiros, Cunha e Jacob (2014), a construção de convergências entre a questão alimentar e nutricional e as demandas de regulação sanitária é um grande desafio a ser enfrentado. É notória a necessidade de ampliação do espectro da vigilância sanitária para responder ao interesse público de promoção da saúde e da alimentação saudável, assim como acompanhar aos avanços ocorridos no âmbito da SAN (CUNHA e JACOB, 2014) 
Neste sentido, a aprovação da Resolução da Diretoria Colegiada $n^{\circ}$ 49/2013 demonstra um avanço em vistas à inclusão produtiva. A mesma visa a segurança sanitária de bens e serviços para promover a geração de renda, emprego, trabalho, inclusão social e o desenvolvimento socioeconômico do país, auxiliando na erradicação da pobreza extrema (ANVISA, 2014; BRASIL, 2011).De acordo com Agência Nacional de Vigilância Sanitária (ANVISA) (2014), essa nova Resolução (RDC no 49/2013) que entrou em vigor um ano após sua publicação,dispõe sobre a regularização para o exercício de atividade de interesse sanitário do microempreendedor individual, do empreendimento familiar rural e do empreendimento econômico solidário, promovendo a criação de elementos facilitadores de inclusão social e econômica através da regularização das atividades descritas na norma.

Sendo assim, este trabalho buscou analisar as condições de produção e o cenário vivido por agricultores familiares e microempreendedores individuais (seja incentivos, fiscalização, dentre outros aspectos), bem como a competência do órgão de Vigilância Sanitária local, em relação às considerações trazidas pela RDC $n^{0}$ 49/2013 em um município do sudoeste do Paraná.

Assim, este artigo inicia com uma contextualização teórica/bibliográfica, seguindo com a descrição metodológica e finalizando com a apresentação e discussão dos resultados, apresentando os casos estudados e sua adequação à RDC $n^{\circ}$ 275/2002, além de analisar a aplicabilidade da RDC $n^{\circ}$ 49/2013, que se propõe a ser mais adequada à realidade das agroindústrias familiares.

\section{DEBATES ENTRE VIGILÂNCIA SANITÁRIA E PRODUÇÃO ARTESANAL: BARREIRAS PARA A LEGALIZAÇÃO DE ALIMENTOS DE PRODUÇÃO ARTESANAL DIANTE DAS NORMAS SANITÁRIAS}

Autores como Friedmann e McMichael (1989), realizam uma análise do processo de desconexão da cadeia alimentar a partir da teoria regulacionista, que especifica a história política do capitalismo entendida a partir da perspectiva da alimentação. Defendem que estaríamos em um terceiro regime alimentar, onde a alimentação e a agricultura passaram a ser organizadas em escala mundial. A especialização da produção agrícola estendida entre continentes abriu um vasto espaço entre onde as pessoas vivem e a origem dos produtos que consomem, entre o trabalho que realizam e os objetos que utilizam. A subordinação dos alimentos ao mercado autorregulado envolve o desligamento das relações econômicas da região e das pessoas. Cada passo da cadeia alimentar e sua complexidade promovem uma forte separação da produção e do consumo de uma comunidade. No entanto, estes processos produzem tensões e crises, o que remete para um regime contemporâneo mais contraditório e complexo que os dois anteriores. Por um lado, ele tem de lidar com a forte concorrência entre as corporações, e, por outro, com os problemas que produziu como as preocupações sociais, ambientais e de saúde.

Em relação ao Brasil, a industrialização dos alimentos se intensificou em meados da década de 1980. Antes disso a produção e o processamento de alimentos eram de pequena escala. $O$ processamento e conservação de matériasprimas como carnes, embutidos, queijos, conservas, compotas, etc., ocorriam principalmente no ambiente doméstico, sendo práticas do dia-dia dos agricultores. Com isso, assegurava-se especialmente a diversidade dos alimentos (CRUZ E SCHNEIDER, 2010).

Com a urbanização essa forma de produzir alimentos passou a ser redimensionada permitindo aumentar a produtividade no intuito de atender a demanda do crescimento populacional. A produção de alimentos passou a ter como 
foco principal a quantidade, substituindo matérias-primas e incrementando o uso de aditivos para tornar os alimentos mais baratos e duráveis. Quanto maior a durabilidade dos produtos, mais centralizada se tornou a produção, de modo que a distribuição se deu através de cadeias longas. Em contrapartida, devido a sucessivos casos de contaminação de alimentos ligados à produção industrial, esse sistema convencional de produção vem sendo questionado nos últimos anos (CRUZ e SCHNEIDER, 2010).

$\mathrm{Na}$ esteira destes cenários e perspectivas teóricas vêm aumentando os debates quanto a qualidade dos alimentos,a defesa e valorização dos produtos tradicionais, bem como, a relocalização da produção e cadeias curtas de distribuição de alimentos. Vem crescendo o interesse pelos produtos artesanais, onde os processos envolvidos são manuais e marcados pela não padronização ou pela pouca utilização da mecanização. Nesses moldes, existe divisão social de trabalho, sua produção na grande maioria é realizada pelas famílias, onde as mesmas possuem conhecimento acerca dos processos, matéria prima, utensílios, elaboração entre outros. Mais que isso, estes conhecimentos são passados de geração para geração, preservando a cultura, os costumes da região, tendo menores impactos em relação aos aspectos socioambientais (CRUZ, 2012).

A forma artesanal de produzir caracteriza-se por um processo de produção com uma dimensão de arte e não meramente técnica. O toque especial que cada produtor dá ao seu produto é o diferencial e o fundamento do artesanal, o que faz cada produto único. O artesanal é centrado no como fazer, na variável humana, na diferenciação. Enquanto que no processo industrial, o fundamento é a padronização do produto, a garantia de que determinada marca não apresenta variação nem em qualidade, nem nas características do produto devido a procedimentos técnicos e operações mecânicas sob rígido controle (SILVEIRA e HEINZ, 2005).

Para Zuin e Zuin (2008) e Silveira (2009), a produção artesanal de alimentos favorece o saber típico da região e de determinadas culturas, bem como o desenvolvimento de agroindústrias familiares envolvendo o saber-fazer das mulheres, principais produtoras desses alimentos. Esta produção é caracterizada por produtos com história, que passam de geração em geração que os foram produzindo e recriando. Marcam uma ação que reúne relações sociais e familiares, num encontro entre o saber e a experiência. Nesse sentido, a produção desses alimentos é uma arte construída ao longo do tempo através da tradição familiar e comunitária.

A valorização da produção artesanal vem sendo defendida por movimentos sociais como o Slow Food, além de ganhar créditos nas pesquisas acadêmicas e debates políticos. Mais que isso, ainda está associada às expectativas dos consumidores em relação aos alimentos que têm sua produção ligada ao rural e aos mitos do natural e do artesanal, de modo a aproximar produtores e consumidores na busca urbana por "imagens dos sabores perdidos" (CRUZ, 2012).Nessa perspectiva, no Brasil, ressaltam-se movimentos tradicionalistas que representam a importância da cultura alimentar por meio de suas festas, como exemplo a culinária e literatura, típicas na região Sul, o movimento tradicional gaúcho, no Norte, as festas do Boi de Parintins (MA), e Nordeste, com o Movimento Armorial (PE) (ZUIN e ZUIN, 2008).

Em outra perspectiva, a produção artesanal também se encontra atrelada à sucessão familiar rural, potencializando a permanência de jovens no campo, uma vez que podem ser donos do próprio negócio, permanecem próximos à família e fazem o que gostam. Nesse sentido, a agricultura familiar potencializa a produção de emprego e renda por meio de um viés socioeconômico (KRUGER et al., 2018). Tal viés é positivo quando considerado que produtores da agricultura familiar comumente sentem-se diminuídos no mercado competitivo em relação aos grandes 
produtores, devido ao crescimento econômico resultante da produção em grande escala que valoriza a produção das commodities em detrimento da produção de pequena escala voltada ao abastecimento interno (BELEM, ALVES, SCHMELLING, 2018).

Dessa forma, frisa-se aqui a importância da discussão acerca da valorização de alimentos tradicionais e/ou artesanais, dado os valores e tendências que apontam para a relocalização da produção de alimentos, aproximação produção-consumo e cadeias curtas de produção e distribuição. Por mais que este modelo de produção e distribuição de alimentos não substitua o modelo de produção em larga escala e considerando que esse movimento é ainda periférico em relação ao sistema hegemônico, deve-se defender as novas tendências que se apresentam como estratégicas para ações que buscam desenvolvimento rural baseado em características e potencialidades intrínsecas de cada região (CRUZ e SCHNEIDER, 2010).

Porém, é notório que uma das questões que tem impedido a comercialização de produtos da agricultura familiar diz respeito às exigências sanitárias. Alimentos obtidos por processos artesanais na maioria das vezes são condenados à informalidade por não passarem por uma inspeção sanitária ou registro em órgão público, devido à inflexibilidade da legislação em relação à pequena escala de produção e impossibilidade de investimentos. É importante considerar que de uma maneira geral, a legislação sanitária foi elaborada a partir da realidade de grandes empresas de alimentos, estabelecendo uma estrutura de processamento que, na maior parte dos casos, está além da capacidade produtiva e financeira dos produtores artesanais (PAULA e FRAVET, 2012; BRASIL, 1997).

Normas sanitárias incompatíveis com a realidade local da produção acarretam a inviabilidade da regularização do estabelecimento produtor de alimento tradicional, devido a pequena escala de produção, de modo a gerar renda insuficiente para alcance destas adequações (CRUZ e SCHNEIDER, 2010).

Sendo assim, políticas públicas de fomento devem ser direcionadas a potencializar a produção da agricultura familiar, bem como, a permitir a permanência destas famílias no campo, objetivando a continuidade da produção de alimentos, e abastecendo assim os mercados locais e regionais. Neste contexto, fazem-se necessárias políticas públicas que promovam a produção e consumo de alimentos com qualidade (SILVA e FERREIRA, 2016).

Pautando-se nestes debates, a RDC no49/2013 foi criada para estabelecer normas para a regularização do exercício de atividades do microempreendedor individual, empreendimento familiar rural e empreendimento econômico solidário ${ }^{4}$,

4 Conforme definido pela Lei Complementar no 123, de 14 de dezembro de 2006 consideram-se microempresas ou empresas de pequeno porte; a sociedade empresária, a sociedade simples, a empresa individual de responsabilidade limitada e o empresário devidamente registrado no Registro de Empresas Mercantis ou no Registro Civil de Pessoas Jurídicas, conforme o caso, desde que: aufira, em cada anocalendário, receita bruta igual ou inferior a $\mathrm{R} \$ 360.000,00$ (trezentos e sessenta mil reais); e no caso da empresa de pequeno porte, aufira, em cada ano-calendário, receita bruta superior a $R \$ 360.000,00$ (trezentos e sessenta mil reais) e igual ou inferior a $\mathrm{R} \$ 3.600 .000,00$ (três milhões e seiscentos mil reais. No que se refere a empreendimentos econômicos solidários, conforme definido pelo Decreto $\mathrm{n}^{\circ} 7.358$, de 17 de novembro de 2010 , os mesmos são definidos por organizações de caráter associativo que realizam atividades econômicas cujos participantes sejam trabalhadores do meio urbano ou rural e exerçam democraticamente a gestão das atividades e a alocação dos resultados. Considera-se agricultor familiar e empreendedor familiar rural aquele que pratica atividades no meio rural, atendendo, simultaneamente, aos seguintes requisitos: não deter, a qualquer título, área maior do que 4 (quatro) módulos fiscais; utilizar predominantemente mão-de-obra da própria família nas atividades econômicas do seu estabelecimento ou empreendimento; tenha percentual mínimo da renda familiar originada de atividades econômicas do seu estabelecimento ou empreendimento, na forma definida pelo Poder Executivo; dirija seu estabelecimento ou empreendimento com sua família (Brasil, 2006). De acordo com a Lei oㅜ 11.718, de 20 de junho de 2008 pode-se entender como regime de economia familiar a atividade em que o trabalho dos membros da família 
que sejam produtores de bens e prestadores de serviços sujeitos à ação da vigilância sanitária (BRASIL, 2013).

A RDC no 49/2013, surgiu após ser submetida à consulta pública em 29 de outubro de 2013, durante Simpósio Brasileiro de Vigilância Sanitária (VI SIMBRAVISA), através do Programa de Inclusão Produtiva com Segurança Sanitária (PIPSS), que objetiva a integração das ações do Sistema Nacional de Vigilância Sanitária (SNVS) aos empreendimentos administrados pela população de menor renda e que possuem maior dificuldade para formalização de suas atividades econômicas (SCHOTTZ, CINTRÃO, SANTOS, 2014).

Segundo a ANVISA (2014), o aspecto educativo e orientador trazido pela RDC no 49/2013 em relação à atuação fiscalizadora sanitária ultrapassa o antigo caráter meramente punitivo, no qual traz a moderna visão do poder estatal. Desta forma, o agente fiscalizador atua ao lado do cidadão, como seu parceiro, orientador e educador, sempre considerando o risco sanitário. Ou seja, a norma é amparadora e facilitadora, porém não permissiva. Além disso, o caráter orientador e educativo sobre matérias de vigilância sanitária deverá dar ênfase aos empreendedores que exerçam atividades de alto risco ${ }^{5}$ (ANVISA, 2014).

Para tais desígnios, a RDC 49/2013 prevê, por parte do SNVS, programas de capacitação com periodicidade regular, voltados à sensibilização e atualização de seus profissionais, sendo focadas no cumprimento de suas diretrizes. Estes agentes devem se envolver não somente à prevenção de riscos à saúde da população, mas também, ao reconhecimento de agentes promotores de desenvolvimento, estimulando o mercado formal e auxiliando na distribuição de renda (ANVISA, 2014).

Ademais, a RDC n49/2013 traz a diretriz direcionada à "proteção à produção artesanal a fim de preservar costumes, hábitos e conhecimentos tradicionais na perspectiva do multiculturalismo dos povos, comunidades tradicionais e agricultores familiares" (BRASIL, 2013, pg. 57). Um dos princípios se refere à razoabilidade, onde os agentes de fiscalização sanitária devem agir com bom senso e moderação, tomando atitudes adequadas, condizentes a realidade dos fatores sociais, culturais e históricos, considerando o risco sanitário (BRASIL, 2013).Segundo a ANVISA (2016) as fiscalizações da vigilância sanitária devem considerar os processos baseados em conhecimentos tradicionais, pois estes saberes e fazeres tradicionais que passam de geração para geração são expressões valiosas da cultura, cuja preservação é também dever do Estado.

Outro aspecto respaldado pela resolução no 49/2013 elucida também, as integrações e articulações dos processos e dados do SNVS com órgãos e entidades, visando impedir a duplicidade de exigências para os empreendimentos, racionalizando, simplificando e padronizando os processos (ANVISA, 2016).

Além do rompimento das punições e posturas mais policialescas que caracterizam a atuação dos agentes fiscalizadores, a RDC no 49/2013 traz a regularização sanitária automática de atividades de baixo risco que compreende as residências, áreas desprovidas de regularização fundiária legal ou com regularização precária, mas, para que isso ocorra, o produtor deve dar acesso ao

apresenta-se indispensável à própria subsistência e ao desenvolvimento socioeconômico do núcleo familiar, de modo a ser exercido em condições de mútua dependência e colaboração, sem a utilização de empregados permanentes (Brasil, 2008). Suplantando a definição legal, a agricultura familiar incorpora uma diversidade de situações específicas e particulares, gerada a partir da relação entre trabalho, propriedade $e$ família, caracterizada por uma categoria extensa que agrupa o campesinato, o agricultor de subsistência, considerando estas categorias como um de produzir e viver em sociedade tendo sua autonomia demográfica, social e econômica (SILVA e FERREIRA, 2016).

5 1ํ A classificação de risco terá como base os dados epidemiológicos, considerando a capacidade dos serviços, os costumes, os conhecimentos tradicionais, a escala de produção e demais fatores relacionados, de acordo com a Classificação Nacional de Atividade Econômica (CNAE) (ANVISA, 2014, pg 34). 
local pelos agentes da vigilância para obter orientações. Além disso, estes produtores ficam isentos de taxas de fiscalização sanitária, para os empreendimentos, produtos e serviços, e deve ser dada tanto no momento da abertura do negócio, como nas renovações (SCHOTTZ, CINTRÃO, SANTOS, 2014; ANVISA, 2016).

Alcançar a formalidade das agroindústrias tende a favorecer não somente os empreendedores, mas também, a sociedade como um todo. A inclusão dos empreendimentos gera aumento da atividade econômica, fortalece o orçamento público, mantém a economia do país em movimento, gera emprego, trabalho e renda, contribuindo para o desenvolvimento local e sustentável das regiões em que atuam, além de preservar os costumes e a cultura local. Portanto, o poder público, tanto na esfera Federal, como também estadual e municipal, tem o dever de estimular e dar suporte para que estes empreendimentos sejam bem sucedidos. Sendo assim, a concretização dos princípios da resolução nº 49/2013 vem para somar e auxiliar nestes aspectos (ANVISA, 2016).

\section{METODOLOGIA}

Trata-se de um estudo de caso de caráter qualitativo e quantitativo, visto que, quantificaram-se os dados obtidos a partir da aplicação do checklist, e da compreensão de falas de atores envolvidos no tema estudado. O mesmo foi desenvolvido em um município da região sudoeste do Paraná no período de outubro a novembro de 20150 modelo de modernização da agricultura domina o ideário da produção agrícola e ainda atua na maior parte da produção de alimentos no mundo, o que chamamos de sistema de agricultura convencional. Entretanto, esse modelo de produção que consiste na exploração irrestrita do solo e dos recursos naturais para obter maior produtividade e rendimento econômico, não leva em conta na maioria das vezes, que a utilização constante de insumos externos e o manejo artificializado dos agroecossistemas podem implicar em problemas irreversíveis aos ecossistemas locais e a na saúde dos consumidores.

\subsection{CENÁRIO DA PESQUISA E DESCRIÇÃO DOS PARTICIPANTES}

O município estudado possui área territorial de $322.217 \mathrm{~km}^{2}$ e localiza-se no sudoeste paranaense, apresentando uma população estimada de 14.289 habitantes (5.711 habitantes vivem no meio rural e 7.421 no meio urbano) (IPARDES, 2016). A atividade econômica que mais oferece emprego são as indústrias em geral, em seguida, o comercio, e por último a agropecuária e construção civil (IPARDES, 2016). Dentre os estabelecimentos agropecuários, destacam-se principalmente a pecuária e a criação de outros animais com 781 estabelecimentos, seguido da lavoura temporária com 579 estabelecimentos. Os principais produtos cultivados na região são soja, milho e trigo. Na produção animal se destaca a produção de leite e ovos de galinha (IPARDES, 2016). Justifica-se a escolha por considerar que este município possui características que são muito comuns no interior do estado do Paraná - população menor que 50.000 habitantes e com produção de alimentos essencialmente proveniente da agricultura familiar.

Foram entrevistadas oito pessoas, sendo um representante da Vigilância Sanitária e sete atores: três fornecedores da alimentação escolar do município, e os outros quatro microempreendedores individuais, manipuladores de alimentos (Quadro 1). 
Quadro 1 - Caracterização dos entrevistados no estudo.

\begin{tabular}{llll}
\hline Entrevistados & $\begin{array}{l}\text { Microempreendedor } \\
\text { individual }\end{array}$ & $\begin{array}{l}\text { Fornecedor } \\
\text { alimentação escolar }\end{array}$ & $\begin{array}{l}\text { Profissional da } \\
\text { Vigilância Sanitária }\end{array}$ \\
\hline Total & 4 & 3 & 1 \\
$\begin{array}{l}\text { Alimentos } \\
\text { produzidos }\end{array}$ & Panificados & $\begin{array}{l}\text { Panificados, ovos, } \\
\text { verduras }\end{array}$ & - \\
\hline
\end{tabular}

Fonte: Elaborado pelas autoras, 2016.

A escolha dos agricultores familiares, microempreendedores individuais foi feita a partir da lista de acompanhamento fornecida pelos profissionais responsáveis do departamento de Vigilância Sanitária do município. Para tanto foram realizadas visitas a estes indivíduos em conjunto com o profissional responsável pela Vigilância Sanitária do município. Nestas visitas eram aplicados os checklist e as entrevistas com os atores envolvidos.

\subsection{INSTRUMENTOS E PROCEDIMENTOS PARA COLETA E ANÁLISE DE DADOS}

Para verificar as condições das agroindústrias utilizou-se a Lista de Verificação das Boas Práticas de Fabricação em estabelecimentos Produtores/Industrializadores de Alimentos (checklist), a qual se propõe a observar itens como: aspectos gerais de recursos humanos; condições ambientais; instalações; edificações e saneamento; equipamentos; além de sanitização e o fluxo de produção. As opções de respostas para tais itens foram classificadas em: "SIM", quando o item estava sendo contemplado; "NÃO" quando o item não estava sendo contemplado e "NÃO SE APLICA" nos casos em que o quesito não se fazia presente (BRASIL, 2002). Este instrumento foi utilizado por meio de observação direta e aplicado apenas aos estabelecimentos de manipuladores de alimentos (três produtores de panificados e um de panificados e sorvete).

Após isso, foram organizados e analisados por meio do software Microsoft Exce/ß versão 2010. A avaliação dos resultados se deu conforme o percentual de adequação encontrado nos aspectos observados. Assim, os estabelecimentos foram classificados de acordo com o sugerido na RDC no 275/2002, em: Grupo 1 - quando apresenta de 76 a 100\% de conformidade; Grupo 2 - quando apresenta 51 a $75 \%$ de conformidade e, Grupo $3-0$ a $50 \%$ de conformidade 6 .

As entrevistas foram realizadas por meio de formulário composto por perguntas semiestruturadas, desenvolvido pelos pesquisadores e diferenciados para os grupos de atores. No caso dos produtores e manipuladores de alimentos, abordaram-se aspectos como: produção e local de aquisição das matérias primas; locais de venda dos produtos; cursos e incentivos à melhoria da qualidade dos alimentos produzidos; visão do produtor em relação ao vigilante de saúde, no que se referem à fiscalização, exigências, orientações e regras estabelecidas; subsídios para atingir adequação dos estabelecimentos produtores de alimentos; aspectos culturais presentes na produção. Para o profissional da Vigilância Sanitária foram levantadas questões sobre informações e treinamentos recebidos acerca da RDC no 49/2013; conhecimento e opinião sobre a nova Resolução; e razoabilidade aplicada nas inspeções destes estabelecimentos.

${ }^{6}$ O percentual de itens atendidos foi obtido pela divisão entre o número de itens em adequação com a legislação, multiplicado por cem, e o número de itens avaliados, tirando-se o número de itens identificados como "NÃO SE APLICA". 
Todas as entrevistas foram gravadas com recurso de áudio e transcritas no software Word® versão 2010. Após isso, foram analisadas utilizando-se o método de análise de conteúdo (BARDIN, 2009).

Esta pesquisa foi desenvolvida a partir da Chamada MCTI-CNPq/MDSSAGI № $24 / 2013$ e respeitou os preceitos éticos. Portanto, todos os participantes assinaram o termo de consentimento livre e esclarecido, concordando com a divulgação dos dados coletados e estando cientes que todos os dados pessoais seriam mantidos em sigilo.

\section{RESULTADOS E DISCUSSÕES}

Os produtores e manipuladores do estudo comercializavam seus produtos em mercados; domicílios locais e/ou em municípios próximos; bem como o PNAE. Salienta-se que no período de estudo nenhum destes possuía licença sanitária expedida pela Vigilância Sanitária devido a inadequações.

Considerando os estabelecimentos em que foi aplicado o checklist da RDC no 275/2002, a Tabela 1 demonstra que o estabelecimento do manipulador A foi o que apresentou maior adequação ao ser classificado no Grupo 2 (51,05\% de conformidades). Outros três estabelecimentos classificaram-se no Grupo 3, com destaque ao estabelecimento $D$, com os menores índices de adequação dos itens avaliados $(25,82 \%)$.

De maneira díspar ao aqui encontrado, Schiavo et al. (2015), ao avaliar pelo mesmo checklist, onze produtores rurais que forneciam alimentos doces para o PAA, em Cardoso Moreira-RJ, encontrou percentual de atendimento aos itens avaliados superior a $51 \%$ (Grupo 2) na maioria (sete) dos onze agricultores. Apenas dois produtores foram classificados no Grupo 3, o que implica em condições precárias para produção.

Tabela 1 - Percentual de itens em conformidade dos estabelecimentos dos manipuladores.

\begin{tabular}{lllll}
\hline Item avaliado & $\mathrm{A}$ & $\mathrm{B}$ & $\mathrm{C}$ & $\mathrm{D}$ \\
\hline Edificações e instalações (\%) & 57,14 & 35,44 & 46,03 & 23,81 \\
$\begin{array}{l}\text { Equipamentos, móveis e utensílios } \\
\text { (\%) }\end{array}$ & 52,63 & 19,05 & 26,32 & 21,05 \\
Manipuladores (\%) & 80,00 & 35,71 & 40,00 & 42,86 \\
Produção e transporte do alimento (\%) & 65,52 & 48,48 & 41,38 & 41,38 \\
Documentação (\%) & 0 & 0 & 0 & 0 \\
\hline
\end{tabular}

Fonte: Elaborado pelas autoras, 2016.

Ainda, por meio da Tabela 1, observa-se que no item referente a "Manipuladores" foi alcançada maior adequação pelos participantes, enquanto "Documentação" não foi atendida, seguido de "Equipamentos, móveis e utensílios", o qual obteve de uma maneira geral, maiores aspectos em inadequações, pelo checklist.

Este último resultado pode ser explicado a partir da observação quanto à presença de equipamentos e móveis adaptados ao invés de planejados. A mesma justificativa pode ser dada ao resultado encontrado para "Edificações e instalações", já que os mesmos, em sua maioria, eram domiciliares, sendo compartilhados para outros afazeres das famílias, o que é considerado inadequado pela RDC 275/2002. 
Salienta-se que dos quatro produtores aqui avaliados, apenas um possuía cozinha separada da cozinha utilizada pela família, a qual não era separada totalmente do domicilio, como recomendado pela regulamentação supracitada.

Estes itens obrigatórios exigidos por esta legislação implicam de forma significativa na não formalização de grande parte destes estabelecimentos aos mercados institucionais. Esta questão abordada na RDC n 275/2002 é contrária o preceito do artigo 12 da RDC no 49/2013, que dentre outros itens, descreve que os órgãos de vigilância sanitária, observando o risco sanitário, poderão regularizar as atividades do microempreendedor individual, do empreendimento familiar rural e do empreendimento econômico solidário, que são instalados em residências (ANVISA, 2014).

Nesse sentido, a aplicação deste método permitiu verificar que os itens "Edificações e instalações", bem como o item "Equipamentos, móveis e utensílios" da RDC no $275 / 2002$, que representam $14,41 \%$ dos itens sugeridos no checklist, não são aplicáveis à realidade local dos produtores demonstrando a inadequação deste instrumento ao público avaliado.

Quando questionado aos produtores entrevistados sobre as exigências solicitadas pela Vigilância Sanitária, três dos quatro produtores inspecionados referiram a necessidade de uma maior razoabilidade dos vigilantes em relação à realidade local de sua produção:

[...] eu acho que é bastante exigente. Eu acho que sim. Eles deviam assim... eu acho que como eles são do município, eles deviam ceder um pouco pra quem tá produzindo aqui né.[...] Porque daí era muita coisa que tinha que muda né. E daí, daí no fim tu gastava um monte" (produtor B).

A partir desta fala é ressaltada a influencia de condições econômicas, para a ocorrência ou não de adequação das estruturas, de acordo com o recomendado pela Vigilância Sanitária do município. Prezotto (1997) aponta que as regulamentações existentes para a produção/elaboração de alimentos levam um nível de estrutura que implica num grande volume de recursos financeiros. Volume este que não se justifica economicamente para uma pequena agroindústria, já que em função de sua pequena escala de produção, ela não gera receita suficiente para retornar o capital investido, tornando inviável o empreendimento.

$\mathrm{Na}$ mesma linha de pensamento, Silveira e Henz (2005), debatem que os programas para implantação de agroindústrias familiares indicam um conjunto de investimentos, instalações e equipamentos necessários para obter-se o aval do poder público. Entretanto, estas alterações propostas para aspectos sanitários e fiscais, geralmente, estão além das expectativas dos agricultores. Mais que isso, o que se observa é que depois de realizados os investimentos, surgem um conjunto de consequências advindas do aumento de escala de produção para se alcançar a capacidade de pagamento necessária. Nesta discussão, os autores ainda citam como barreiras na produção artesanal:

[...] incompatibilidade entre disponibilidade de matéria-prima e produção almejada, a concorrência da atividade agroindustrial com as demais atividades realizadas na unidade de produção familiar por recursos de mão-de-obra, capital e, eventualmente, terra, além da descaracterização do processo artesanal de produção ao adotar-se um padrão industrial (originado na introdução de máquinas e equipamentos que permitem um 
controle rígido dos procedimentos de produção) (SILVEIRA e HEINZ, 2005, pg.2).

Os efeitos acima elencados levam a refletir sobre a concepção dos programas de estímulo à agroindústria familiar e/ou a fiscalização da Vigilância Sanitária pautada em grandes produções, dando-se ênfase à importância de uma maior flexibilização das exigências ao público aqui tratado. Nesse intermédio, entende-se que o objetivo trazido pela RDC no 49/2013, surge como uma importante iniciativa da ANVISA, visto que dentre suas principais inovações estão a razoabilidade das exigências aplicadas; proteção à produção artesanal e o caráter orientador e educativo, prevendo, a disponibilização de orientações ou instrumentos norteadores para os empreendedores, com ênfase aos que exerçam atividades de alto risco (BRASIL, 2013). No entanto, ainda existem caminhos a serem trilhados para que estes objetivos sejam realmente alcançados.

Tratando-se destes princípios, mesmo que o profissional da vigilância sanitária entrevistado tenha citado determinada razoabilidade nas suas condutas (o que foi afirmado por dois dos quatro entrevistados quanto a este aspecto), o mesmo relata a falta de informações sobre a Resolução no 49/2013, afirmando só ter tido conhecimento da mesma, em função desta pesquisa. Quanto a isso, ressalta-se que esta Resolução está em vigor desde abril de 2014 (BRASIL, 2013), sendo um tanto curioso que os profissionais responsáveis por isso não tenham recebido informações após o período decorrido.

Nesse quesito, Schottz, Cintrão e Santos (2014) referem que, para colocar esta mudança de paradigma em prática, é necessário que a ANVISA invista em ações de formação e capacitação das Vigilâncias Sanitárias estaduais e municipais. Ou seja, não ocorrerá a aplicabilidade da RDC no 49/2013 se o profissional de Vigilância Sanitária não conhecer de maneira concreta a Resolução, seus princípios e diretrizes.

Mesmo assim, segundo considerações feitas pelo profissional entrevistado, tem se tentado seguir as recomendações trazidas pela RDC no49/2013, mesmo sem ter tido o conhecimento dela:

\begin{abstract}
Que a gente acaba tentando fazer de uma forma que a gente mantenha a segurança de alimento, o máximo possível, mas que a gente consiga, é...fixar essa inspeção na realidade desse produtor. Porque se a gente for pedir pra fazer todas as adequações que é necessário pela RDC no275, esse pequeno produtor vai ter que parar de produzir, porque ele não vai ter condições financeiras pra fazer essas adequações. [...] Agora eu não posso mexer na questão receita, na questão do que é bom, o que é ruim. (profissional da VS)
\end{abstract}

Tal afirmação considera a flexibilidade em relação à regulamentação existente (RDC no 275/2002) e a proteção da produção artesanal. Porém, quando respaldada a diretriz $\mathrm{V}$ - que se refere à proteção da produção artesanal a fim de preservar costumes, hábitos e conhecimentos tradicionais na perspectiva do multiculturalismo dos povos, comunidades tradicionais e agricultores familiares -, é percebido certa contradição, ao considerar os relatos apresentados pelos produtores sobre a restrição do uso de algumas de suas matérias primas.

[...] as farinha, nóis plantamo trigo. Trazemo num muínho lá [...] O ovo eu compro ali [..] é caipira [...] Porque macarrão sem caipira não fica bão né (produtor B). 
[...] que a gente não pode mais usá, esses ovos caipiras porque tem bactéria [...] que tinha que começá usá os ovos em pó, que era mais garantido. Mas como é que tu vai fazer uma bolacha com um pó? (produtor C)

Tratando-se da produção artesanal de alimentos, Silveira e Heinz (2005), ressaltam ser necessário impedir a perda do caráter artesanal da produção, visto que se trata de um produto diferenciado e que pode sustentar uma estratégia de desenvolvimento da agroindústria familiar. Mesmo assim, neste estudo, observouse que a produção de alimentos a partir de matérias primas do próprio produtor aparece como uma dificuldade para adequações dos mesmos às exigências solicitadas. É o caso, especificamente de agricultores manipuladores de alimentos, onde dois dos quatro entrevistados que manipulam alimentos referiram utilizar matérias primas produzidas no domicílio, fato este que nem sempre é exposto para o profissional fiscal da Vigilância Sanitária, a fim de não haver proibições:

[...] ela proibiu eu usa ovo caseiro né, dai proibiu usa a manteiga [...] E eu não contei que eu ponho o queijo caseiro pra elas, se contá é capais delas cortá né. (produtor B)

Dentre os aspectos defendidos pelos produtores em relação ao uso de ingredientes próprios, puderam ser observadas questões econômicas (redução de custos em matérias primas), culturais e nutricionais (manutenção da identidade cultural do alimento, garantia da qualidade organoléptica, redução de compostos indesejáveis nos produtos finais), além de questões relacionadas à procedência dos alimentos:

\footnotetext{
Que nem na época que eu tinha galinha eu ajuntava, esperava elas ponha pra mim gasta. Fui no mercado, comprei uma dúzia de ovo peguei oito podre [...] elas exigem aquilo da gente: puro, natural casero [...] não tem, se tu for vê essas coisa casera é melhor, não tem química não tem nada né. [...] Imagina, tu vê nossas criação ali que tudo lisinho, bonito, limpo, daí a gente sabe o que tá comendo né. Então... e daí é que nem o ovo, que nem a mantega... (produtor $\mathrm{B}$ )
}

Diante das falas anteriores, são observados aspectos já trazidos no estudo de Cruz e Schneider (2010), bem como de Belem, Alves e Schmeling (2018) onde as relações de produção e consumo de alimentos, baseadas em cadeias curtas, passam a ser pautadas na confiança, troca de saberes, localidade, qualidade e transparência, significando a acuidade da procedência dos produtos e matérias primas, relatado pela entrevistada. Em uma perspectiva de medos e incertezas, o próximo, o artesanal e o tradicional passam a ser a opção que oferece garantias aos consumidores, assim como para os produtores.

O consumo de alimentos naturais com menores graus de processamento, saudáveis e tradicionais é um dos aspectos importantes ligados a SAN. No entanto, quando se exige dos produtores de alimentos tradicionais, o uso de ingredientes fiscalizados e legalizados pela legislação, os mesmos são estimulados a produzirem seus produtos a partir de matérias primas majoritariamente adquiridas de terceiros. Nesse sentido, os alimentos com tais restrições de ingredientes, também poderiam perder sua qualidade final e identidade cultural (BRASIL, 2014; BRASIL, 2006; CRUZ e SCHNEIDER, 2010). 
As regulamentações para a venda de panificados, tanto para o PAA quanto PNAE, por exemplo, exigem que para que o produto seja considerado como da agricultura familiar, seus ingredientes também sejam oriundos da propriedade do agricultor familiar (BRASIL, 2014; BRASIL, 2006; CRUZ e SCHNEIDER, 2010).

Neste quesito, o profissional da Vigilância Sanitária também admite uma situação difícil vivenciada no seu cotidiano, demonstrando-se ciente e incomodada pela disparidade de regulamentações existentes em relação ao mesmo tema:

[...] você pega agricultores que produzem em casa isso. E você vai pedir pra eles comprar o ovo de outra pessoa pra eles fazer o macarrão que eles vendem? Só que esse ovo dele não tem inspeção [...] a gente chegou a um ponto que a gente tá estrangulando o agricultor, que é quem mantém a nossa economia municipal [...] a Vigilância não consegue agir da forma que ela deveria agir, ou seja, aplicar a RDC e fazer com que tudo se enquadre. Por que? Porque a gente estrangula o outro setor. (profissional da VS)

As questões tornam-se conflitantes no momento em que a indefinição de determinadas regulamentações fazem com que a Vigilância Sanitária interfira na realização da SAN. Como observado, as confluências e ambiguidades entre os diversos argumentos trazidos por distintas regulamentações de maneira aberta, resultam em uma situação confusa, tanto para o profissional da Vigilância Sanitária, quanto para o produtor de alimentos, demonstrando a necessidade de maiores avanços e coerência das orientações.

Nessa situação, o profissional relata a necessidade de aprimoramento da RDC no 49/2013, visto que mesmo buscando o alcance das suas diretrizes, os caminhos apresentam-se ainda desfragmentados, não permitindo seu posicionamento de maneira condizente e ética:

Eu acredito que ainda não tem uma coisa palpável pra Vigilância Sanitária [...] que a ANVISA defina pra gente são roteiros que a gente consiga chegar e adequar à realidade da pessoa. [...] a 275 , ela tem um roteiro de inspeção, que vai dizendo sim ou não. Lógico que foge muito da realidade do pequeno produtor. Eu não consigo adequar ele a aquele roteiro, da 275 [...] (profissional da VS)

Por outro lado, a recomendação trazida pela RDC no 275/2002, quanto à necessidade rótulos de alimentos, foi apontado positivamente de maneira unânime pelos produtores entrevistados. Segundo os mesmos, a adequação deste quesito, permitiu maior amplitude na divulgação do produto, agregando qualidade na concepção dos consumidores e maiores benefícios para a venda:

Bastante gente olha lá: não essas são lá do interior, eu conheço [...] tem gente que liga e pede bolacha. (produtor B)

[...] ali é bom porque vamos supor, muita gente vende o produto ruim, o envenenado, o que, se dá algum problema eles sabem a quem recorre né. (produtor $A$ )

Cruz e Bellé (2012), questionaram consumidores acerca da confiança em relação aos produtos rotulados, onde $76,36 \%$ responderam que se sentem confiantes e $23,64 \%$ não se sentem confiantes. Com relação à satisfação da compra de um produto rotulado, constatou-se que $84,75 \%$ se sentiam satisfeitos. Para 
Machado et al. (2008), a decisão da compra ou não de um produto exige que o consumidor trace um caminho, com um processamento de informação, entre informações que recebe do meio externo e aquelas já retida em sua memória. Nesse sentido, a importância dada à rotulagem é um dos aspectos facilitadores para a valorização e venda do alimento tradicional.

Em relação à qualidade destes produtos, ressalta-se que a SAN inclui, dentre outros aspectos, o respeito à diversidade cultural. Para Teo e Triches (2016) a qualidade dos alimentos não incide apenas do ponto de vista microbiológico e nutricional, mas também em questões culturais associadas às escolhas alimentares. Portanto, a partir dos avanços recentes nesta temática, torna-se importante extrapolar a ideia de que alimento de qualidade é o alimento unicamente inócuo. Claramente, a inocuidade apresenta grande importancia na qualidade dos alimentos, no entanto, na maneira que vem sendo considerada, está resultando na inviabilização do acesso dos produtos artesanais ou coloniais no mercado formal, afetando assim a continuidade cultural, um patrimônio imaterial que está sendo perdido.

Quanto a isso, destaca-se que os aspectos culturais foram enfatizados de maneira relevante por quatro dos seis produtores entrevistados, frisando-se aos meios utilizados para a fabricação e plantio e as preparações em si (relacionados ao modo de preparo e receitas).

[...] agora essa bolacha caseira que eu falo que é o que mais eu vendo né [...] veio sei lá, da mãe, da nona, sei lá... isso ai veio lá das tia. [..] isso ai é antigona. Tem gente que fala: é bolacha da vovó né. (produtor $B$ )

[...] as cuca eu faço como eu aprendi com minha mãe né. (produtor A)

[...] tudo é de antigo, bolacha caseira é antiga, bolacha de milho antiga, que as nona fazia, que eles dizem "tempo da minha mãe minhas nona,o macarrão essas coisas, é tudo de antigamente essas coisas. (produtor $\mathrm{C}$ )

Os temperos, principalmente os temperos né. A gente procura manter os temperos sempre fresquinhos, não usar outros, tipo caldo, caldo essas coisas assim. (produtor D)

Segundo Picolotto e Brandenburg (2013), o fator cultural envolvido na produção artesanal de alimentos é relevante ao delineamento de um conceito de qualidade individual destes produtos, o qual inclusive é referenciado pelos consumidores. Segundo os mesmos autores, a valorização dos produtos elaborados de maneira artesanal, a partir de formas tradicionais de produzir herdadas dos antepassados (os colonos), evidencia a valorização positiva para a agricultura familiar ou outro produtor, reforçando suas raízes e seus produtos típicos. entrevistas:

Tais argumentos também foram expostos pelos interlocutores durante as

E é uma questão cultural também. Você pega muitas pessoas aqui do nosso município que não gostam de comprar bolacha no mercado. Eles gostam de comprar de fulano que faz em casa [...] porque mantém aquele gosto, aquela coisa de vó, aquela coisa de mãe e que todo mundo gosta né. (profissional da VS)

Triches e Schneider (2012b), apontam que a concepção dos consumidores acerca da qualidade dos alimentos também está relacionada ao conhecimento e a procedência do mesmo. Ou seja, para os consumidores, ser superior, 
nutricionalmente falando, remete não somente à composição do alimento em si, mas a todo o conhecimento acerca do produtor e processo que envolve a produção destes alimentos.

A concepção de qualidade de um alimento para o consumidor se sobrepõe ao aspecto apenas de segurança, e sim depende das escolhas relacionadas às questões de identidade e de saúde, bem como nas questões ecológicas, morais, ou ainda no atendimento ao seu paladar. Nesse sentido, a qualidade dos alimentos compõe várias dimensões e critérios, e não a um único conceito. Assim sendo, a qualidade representa um processo social ou um processo de qualificação, ou seja, é algo construído, e não dado (TRICHES e SCHNEIDER, 2012b).

Por outro lado, segundo os entrevistados, também houve aprimoramentos, principalmente em relação aos modos culturais de manipulação dos alimentos em decorrência de restrições trazidas pela Vigilância Sanitária com:

[...] a gente tinha um hábito né. Mas dai agora que a gente começou vender, tem que ser outro hábito né. Tipo assim, o jeito de armazena os produto né, é diferente do que a gente aprendeu, é diferente. (produtor D)

Cruz e Schneider (2010) defendem que as características dos produtos tradicionais variam de acordo com a região produtora e também em relação aos produtores, evidenciando distintos sistemas de produção de um mesmo alimento. Consequentemente também existem maneiras individuais de vivenciar e trabalhar com as questões alimentares. Nesse sentido, reforçam a necessidade de sistemas de regulamentação que levem em conta a diversidade regional, de modo a não padronizar também a produção tradicional.

É fundamental um roteiro específico aos profissionais da Vigilância Sanitária, a fim de definir quais os procedimentos são necessários para que no seu trabalho seja alcançada a qualidade dos alimentos sem agredir os princípios que a resolução RDC n-49/2013 determina. Seguindo Viana e Triches (2015), pode-se considerar que a resolução RDC 275/2002, diante das normativas sanitárias atuais, representa em seus itens os padrões de qualidade para o processamento de alimentos, que fortalecem a lógica excludente e concentradora. Assim, abandonamse os sistemas alimentares alternativos, como as agroindústrias familiares, cujo apelo social busca produtos diversificados, artesanais, de conhecimentos tradicionais e socialmente includentes (CRUZ e SCHNEIDER, 2010).

Embora a RDC no49/2013 ainda não tenha disponibilizado um cronograma ou um checklist específico no nível federal para aplicar aos estabelecimentos de produção de alimentos tradicionais, a mesma disponibiliza orientações a serem seguidos para que seja realizada a formalização legal destes estabelecimentos, quando determina que os órgãos de Vigilância Sanitária classifiquem ${ }^{7}$ os níveis de risco das atividades econômicas sem baixo e alto risco sanitário. As atividades de baixo risco exercidas pelos empreendimentos poderiam ser automaticamente regularizadas perante os órgãos de vigilância sanitária, mediante alguns procedimentos $^{8}$ citados nas suas normas. No entanto, a resolução, fugindo do

\footnotetext{
${ }^{7} \mathrm{~A}$ classificação de risco terá como base os dados epidemiológicos, considerando a capacidade dos serviços, os costumes, os conhecimentos tradicionais, a escala de produção e demais fatores relacionados, de acordo com a Classificação Nacional de Atividade Econômica (CNAE), prevista nas Resoluções IBGE/CONCLA № 01 de 04 de setembro de 2006 e no 02, de 15 de dezembro de 2006 e, quando conveniente, pela Classificação Brasileira de Ocupações - CBO, instituída pela Portaria no 397 do Ministério do Trabalho e Emprego, de 9 de outubro de 2002 (ANVISA, 2014, pg 34).

8 | - conclusão do procedimento especial de registro e legalização disponível no Portal do Empreendedor, pelo microempreendedor individual. II - apresentação dos documentos previstos no art. 6ำ ao órgão de
} 
estereótipo da fiscalização punitiva, ressalta sobremaneira o caráter orientador e educativo, prevendo o fomento a atividades com este teor, com ênfase aos estabelecimentos que exerçam atividades de alto risco (ANVISA, 2014).

Apesar de alguns impasses citados anteriormente, a resolução RDC $n^{\circ}$ 49/2013 vem fortalecera produção diversificada de alimentos pela agricultura familiar e os circuitos de mercado locais, corroborando para a construção de um modelo de desenvolvimento equitativo e sustentável e para a promoção da alimentação adequada e saudável. Além deste fortalecimento, a Resolução acrescenta ainda mais as conexões entre regulação sanitária e os padrões de consumo de alimentos e desenvolvimento social e econômico (SCHOTTZ; CINTRÃO; SANTOS, 2014).

\section{CONSIDERAÇÕES FINAIS}

Os resultados aqui encontrados apontam para a inadequação sanitária de agricultores familiares e microempreendedores individuais em relação ao instrumento de fiscalização (checklist) utilizado pela Vigilância Sanitária, referente à RDC 275/2002, o que implica em cobranças desvinculadas da realidade de pequenas agroindústrias familiares. Também se verificou contradições entre regulamentações, sem o devido esclarecimento/capacitação dos próprios profissionais que atuam na Vigilância Sanitária dos municípios, prejudicando o alcance geral dos aspectos trazidos pela Resolução 49/2013. Destacam-se confluências e ambiguidades entre as diversas recomendações trazidas por distintas regulamentações que de maneira aberta resultam em uma situação confusa, tanto para o profissional da Vigilância Sanitária, quanto para o produtor de alimentos, influenciando na dificuldade do alcance de determinados aspectos inclusos na garantia de SAN.

Este trabalho permitiu compreender que há necessidade de avanços na área das regulamentações para a produção/elaboração e venda de alimentos, quando considerada a produção artesanal/agroindústrias de alimentos de pequeno porte. Quanto a estes aspectos podem ser ressaltados em especial, impasses econômicos, culturais, ambientais e sociais, em função de sua pequena escala de produção.

Diante do estudo, quando se argumenta sobre a aplicação da RDC n49/2013, no que se refere à "mudança de paradigma", direciona-se a uma mudança do SNVS para uma posição mais orientadora do que punitiva, seguindo assim os princípios para a proteção da produção de alimentos tradicionais e agricultura familiar, sem abrir mão das questões de saúde pública. Estas revisões das normativas sanitárias são necessárias também para permitir a formalização destes estabelecimentos e o acesso aos mercados formais e institucionais como o PNAE e PAA e a inclusão social de agricultores familiares e pequenos empreendedores.

Esta ação abre os caminhos para a promoção do desenvolvimento social quando se mantêm os saberes, cultura, tradição e costumes da região, agrega ainda mais a Política de SAN, bem como, a economia, ao gerar renda tanto para os produtores envolvidos como para a região.

Pontua-se também que esta Resolução vem para que se discuta, articule, e dialogue com os órgãos da saúde, ambiente, agricultura, educação, ou seja, a

vigilância sanitária ou órgão responsável pela simplificação e integração de procedimentos, pelo empreendimento familiar rural e pelo empreendimento econômico solidário. Art. 8ำ A regularização dos empreendimentos cujas atividades sejam de alto risco seguirá os procedimentos ordinários praticados pelos órgãos de vigilância sanitária (ANVISA, 2014, pg 33). 
sociedade em geral. Assim interligando preceitos de SAN, para que se fortaleçam cada vez mais suas ações, políticas e programas que potencializem uma interação positiva entre a questão alimentar e a equidade social.

O presente estudo teve limitações para investigar a totalidade de microempreendedores individuais, empreendimentos familiares rurais e de empreendimentos econômicos solidários presentes no município estudado, mas buscou identificar de forma ampla e aprofundada a complexidade do tema. Por outro lado, aponta para a necessidade de novos estudos em outras realidades e com outros delineamentos de pesquisa para que se possa avançar nas políticas e ações relacionadas à saúde pública e ao desenvolvimento social.

\section{REFERÊNCIAS}

ANVISA. Agência Nacional de Vigilância Sanitária. Inclusão Produtiva com segurança sanitária: RDC 49/2013. 2014.

ANVISA. Agência Nacional de Vigilância Sanitária. Inclusão Produtiva com Segurança Sanitária: Orientação para Gestores de Políticas Públicas Municipais e Trabalhadores da Vigilância Sanitária. 2016.

BALEM, T.A.; ALVES, E.O.; SCHMELLING, G.S. Os desafios da produção agroecológica e da construção de uma estratégia de mercado de circuito curto através da entrega domiciliar de produtos. Extensão Rural, Santa Maria, v.25, n.4, p.20-39, out./dez. $2018 . \quad$ Disponível em: https://periodicos.ufsm.br/extensaorural/article/view/34540/pdf. Acesso em: 22 nov. 2019.

BARDIN, L. Análise de conteúdo. Lisboa, Portugal; Edições 70, LDA, 2009.

BRASIL. Lei no 11.346, de 15 de setembro de 2006. Cria o Sistema Nacional de Segurança Alimentar e Nutricional - SISAN com vistas em assegurar o direito humano à alimentação adequada e dá outras providências. Diário Oficial da União. 18 set 2006.

BRASIL. Resolução - RDC $\mathbf{n}^{\circ}$ 49, de 31 de outubro de 2013. Dispõe sobre a regularização para o exercício de atividade de interesse sanitário do microempreendedor individual, do empreendimento familiar rural e do empreendimento econômico solidário e dá outras providências.2013.

BRASIL. Portaria no. 326, de 30 de julho de 1997. Aprova o Regulamento Técnico sobre as Condições Higiênico-Sanitárias e de Boas Práticas de Fabricação para estabelecimentos Produtores/Industrializadores de Alimentos. Brasília, DF. 1997.

BRASIL. Decreto no 7.492, de 02 de junho de 2011. Institui o Plano Brasil Sem Miséria. Brasília, 2 de junho de 2011.

BRASIL. Lei complementar no 123, de 14 de dezembro de 2006. Capítulo II da definição de microempresa e de empresa de pequeno porte. 2006.

BRASIL. Lei $n^{\circ}$ 10.406, de 10 de janeiro de 2002. livro I das pessoas título das pessoas naturais capítulo I da personalidade e da capacidade. 2002. 
BRASIL. Resolução $n^{\circ}$ 32, de 10 de agosto de 2006. Estabelece as normas para a execução do Programa Nacional de Alimentação Escolar - PNAE. 2006.

BRASIL. Lei no 11.326, de 24 de julho de 2006. Presidência da república casa civil subchefia para assuntos jurídicos subchefia para assuntos jurídicos. 2006.

BRASIL. Decreto no 7.358, de 17 de novembro de 2010. Presidência da república casa civil subchefia para assuntos jurídicos subchefia para assuntos jurídicos. 2010.

BRASIL. Resolução RDC no 275, de 21 de outubro de 2002. Dispõe sobre o Regulamento Técnico de Procedimentos Operacionais Padronizados aplicados aos Estabelecimentos Produtores/Industrializadores de Alimentos e a Lista de Verificação das Boas Práticas de Fabricação em Estabelecimentos Produtores/Industrializadores de Alimentos. Diário Oficial da União; 23 de outubro de 2003.

BRASIL. Guia alimentar para a população brasileira. Ministério da Saúde, Secretaria de Atenção à Saúde, Departamento de Atenção Básica. 2.ed. Brasília: Ministério da Saúde. 2014. Disponível em: http://bvsms.saude.gov.br/bvs/publicacoes/guia_alimentar_populacao_brasileira_2ed .pdf. Acesso em: 16 out. 2015.

BEVILAQUA, K.; TRICHES,M. T. Implicações da venda de gêneros alimentícios ao Programa de Alimentação Escolar nos aspectos de renda e organização dos agricultores familiares. Segurança Alimentar e Nutricional, Campinas, v. 21, n. 2 , pg. 448-460. 2014.

COSTA, E. A. Fundamentos da vigilância sanitária. In: COSTA, E. A. Vigilância Sanitária: temas para debate. Salvador: EDUFBA. 2009.

CRUZ, F T.; SCHNEIDER, S. Qualidade dos alimentos, escalas de produção e valorização de produtos tradicionais. Revista Brasileira de Agroecologia, Universidade Federal do Rio Grande o Sul, Porto Alegre/RS, v. 5 n. 2, p. 22-38. 2010.

CRUZ, C. M.; BELLÉ, T.R.L. Análise do comportamento e conhecimento de produtores e consumidores quanto à rotulagem de alimentos comercializados em feira colonial no Noroeste do Estado do Rio Grande do Sul. Biblioteca Digital Unijuí. 2012.

CRUZ, F. T. Produtores, consumidores e valorização de produtos tradicionais: um estudo sobre qualidade de alimentos a partir do caso do Queijo Serrano dos Campos de Cima da Serra-RS. 2012. Porto Alegre. Tese (Doutorado em Desenvolvimento Rural) - Programa de Pós-graduação em desenvolvimento Rural. Universidade Federal do Rio Grande do Sul, Faculdade de ciências Econômicas.

DAROLT, M.R. Circuitos curtos de comercialização de alimentos ecológicos: reconectando produtores e consumidores. In: NIERDELE, P.A.; ALMEIDA, L.; VEZZANI, F.M. (ORGs). Agroecologia: práticas, mercados e políticas para uma nova agricultura. Curitiba: Kairós. 2013. 
DE PAULA, N. M.; FRAVET, F. F. M. F. Diagnóstico das condições higiênicosanitárias em estabelecimentos produtores de doces artesanais. Cadernos de PósGraduação da FAZU, Frutal, v. 2. 2012.

FOOD AND AGRICULTURE ORGANIZATION OF THE UNITED NATIONS (FAO). Alimentación escolar y lasposibilidades de compra directa de la agricultura familiar. Estudio de caso em ocho países. Fortalecimiento de Programas de Alimentación Escolar em el Marco de la Iniciativa América Latina y Caribe Sin Hambre 2025. 2013.

FRIEDMANN, H., McMICHAEL, P. Agriculture and State System. Sociologia Ruralis, v.29, n.2, p.93-117, 1989.

GUZZATTI, T. C.; SAMPAIO, C. A. C.; TURNES, V. A. Novas Relações entre Agricultores Familiares e Consumidores: Perspectivas Recentes no Brasil e na frança. Organizações Rurais \& Agroindustriais, Lavras, v. 16, n. 3, p. 363375.2014 .

GABRIEL, C. G. et al. Regulamentação da comercialização de alimentos no ambiente escolar: análise dos dispositivos legais brasileiros que buscam a alimentação saudável. Revista do Instituto Adolfo Lutz (Impresso),São Paulo, v. 71 , n. 1, p. 11-20. 2012

IPARDES. Instituto Paranaense de Desenvolvimento Econômico Social. Caderno Estatístico. $\quad$ Abril, 2016. em:http://www.ipardes.gov.br/cadernos/MontaCadPdf1.php?Municipio=85650. Acesso em: 08 dez. 2015.

KRUGER, S.D.; SILVA, M.A.L; MORES, G.V. PETRI, S.M. Fatores determinantes para a sucessão familiar em estabelecimentos rurais da região oeste de Santa Catarina. Extensão Rural, v.25, n.4, out./dez. 2018.

MEDEIROS, M.A.T.; CUNHA, D.T.; JACOB, S.C. Vigilância Sanitária e Segurança Alimentar e Nutricional: desafios no cenário brasileiro. Vig. Sanit. Debate, v. 2, n. 4, p. 2-3. 2014.

MACHADO, S.S. et al. Comportamento dos consumidores com relação à leitura de rótulo de produtos alimentícios. Alimentos e Nutrição Araraquara, v. 17, n. 1, p. 97-103. 2008.

PEPE, V. L. E. et al. A produção científica e grupos de pesquisa sobre vigilância sanitária no CNPq. Ciência e Saúde Coletiva, v. 15, n. Supl. 3, p. 3341-50, 2009. 2010.

PICOLOTTO, E.L.; BRANDENBURG, A. Sindicalismos da agricultura familiar, modelos de desenvolvimento e o tema ambiental. In: NIERDELE, P.A.; ALMEIDA, L.; VEZZANI, F.M. (ORGs). Agroecologia: práticas, mercados e políticas para uma nova agricultura. Curitiba: Kairós. 2013.

PREZOTTO, L. L. A agroindustrialização de pequeno porte: higiene, qualidade e aspectos legais. Revista Agropecuária Catarinense. Florianópolis, v. 10, n. 4, p. 813. 1997. 
SILVEIRA, P. R. C. et al. A construção dos mercados na produção artesanal de alimentos: os circuitos curtos de comercialização. In: Congresso Brasileiro de Sociologia. Rio de Janeiro/ RJ.2009.

SILVA, T. C.; FERREIRA, P. R. O Programa de Aquisição de Alimentos sob a ótica dos atores sociais envolvidos. Revista Desenvolvimento em Questão, Editora Unijuí, Ano 14, n. 33, p. 301-329, mar. 2016. Disponível em: https://www.revistas.unijui.edu.br/index.php/desenvolvimentoemquestao/article/view/ 3041. Acesso em: 22 nov. 2019.

SILVEIRA, P.R.C.; HEINZ, C.U. Controle de qualidade normativo e qualidade ampla: princípios para re-estruturação e qualificação da produção artesanal de alimentos. In: CONGRESSO INTERNACIONAL DE DESENVOLVIMENTO RURAL E AGROINDÚSTRIA FAMILIAR. São Luís Gonzaga-RS, Anais... São Luis Gonzaga: UERGS, 2005.

SCHOTTZ, V; CINTRÃO, R. P; SANTOS, R. M. Convergências entre a Política Nacional de SAN e a construção de normas sanitárias para produtos da Agricultura Familiar. Revista Vigilância Sanitária em Debate, v. 2, n. 4, p. 115-123.2014. Disponível em: https://visaemdebate.incqs.fiocruz.br/index.php/visaemdebate/article/view/461. Acesso em: 22 nov. 2019.

SOUZA, G. S.; COSTA, E. A. Considerações teóricas e conceituais acerca do trabalho em vigilância sanitária, campo específico do trabalho em saúde. Ciencia e Saúde Coletiva, v. 15, n. Supl. 3, p. 3329-3340. 2010.

SCHIAVO, N. C. B.; FRANÇA, L.F.; NASCIMENTO, J. S. Diagnóstico das condições higiênico-sanitárias da produção de doces por agricultores familiares do Programa de Aquisição de Alimentos no município de Cardoso Moreira, RJ. Vigilância Sanitária em Debate. Rio de Janeiro. v. 3, n. 1, p. 135-143. 2015.

TEO, C. R. P. A.; TRICHES, R. M. Alimentação escolar: construindo interfaces entre saúde, educação e desenvolvimento. Chapecó: Argos, 2016.

TRICHES, R. M.; SCHNEIDER. S. Reconstruindo o "elo perdido": a reconexão da produção e do consumo de alimentos através do Programa De Alimentação Escolar no município de Dois Irmãos (RS)". Segurança Alimentar e Nutricional, Campinas, v. 17, n. 1 p. 1-15. 2010. Disponível em: https://periodicos.sbu.unicamp.br/ojs/index.php/san/article/view/8634796/2715. Acesso em: 22 nov. 2019.

TRICHES, R. M. SCHNEIDER, S.O Papel da qualidade dos alimentos na construção de mercados locais: o caso da alimentação escolar. In: $50 \cong$ CONGRESSO DA SOBER- SOCIEDADE BRASILEIRA DE ECONOMIA, ADMINISTRAÇÃO E SOCIOLOGIA RURAL, AGRICULTURA E DESENVOLVIMENTO RURAL COM SUSTENTÁBILIDADE, 50, Anais... Vitória.2012.

VIANA C. E.; TRICHES VIANA. Os conflitos com Normativas Sanitárias: Um Debate sobre as Diferentes Faces da Qualidade dos Alimentos. 5o Simpósio de Segurança Alimentar Alimentação e Saúde, Bento Gonçalves/RS. 2015. 
ZUIN, L. F. S.; ZUIN, P. B. Produção de Alimentos Tradicionais Contribuindo para o Desenvolvimento Local/Regional e dos Pequenos Produtores Rurais. Revista Brasileira de Gestão e Desenvolvimento Regional, Taubaté, v. 4, n. 1, p. 109127, jan./abr. 2008. Disponível em: http://www.rbgdr.net/012008/artigo5.pdf. Acesso em: 22 nov. 2019. 